\title{
Are Resilient Occupational Therapists at Low Risk of Burnout? A Structural Equation Modeling Approach Combined with Latent Profile Analysis in a Greek Sample
}

\author{
Theodoros Kyriazos $^{1 *} \mathbb{1}$, Michalis Galanakis ${ }^{1}$, Aikaterini Katsiana ${ }^{2}$, Vaggelis Saprikis ${ }^{3}$, \\ Dimitrios Tsiamitros ${ }^{4}$, Anastassios Stalikas ${ }^{1}$ \\ ${ }^{1}$ Department of Psychology, Panteion University, Athens, Greece \\ ${ }^{2}$ Department of Occupational Therapy, University of Western Macedonia, Ptolemaida, Greece \\ ${ }^{3}$ Department of Management Science and Technology, University of Western Macedonia, Kozani, Greece \\ ${ }^{4}$ Department of Electrical \& Computer Engineering, Faculty of Engineering, University of Western Macedonia, Kozani, Greece \\ Email: ^th.kyriazos@gmail.com
}

How to cite this paper: Kyriazos, T., Galanakis, M., Katsiana, A., Saprikis, V., Tsiamitros, D., \& Stalikas, A. (2021). Are Resilient Occupational Therapists at Low Risk of Burnout? A Structural Equation Modeling Approach Combined with Latent Profile Analysis in a Greek Sample. Open Journal of Social Sciences, 9, 133-153.

https://doi.org/10.4236/jss.2021.96012

Received: May 10, 2021

Accepted: June 19, 2021

Published: June 22, 2021

Copyright $\odot 2021$ by author(s) and Scientific Research Publishing Inc. This work is licensed under the Creative Commons Attribution International License (CC BY 4.0).

http://creativecommons.org/licenses/by/4.0/

(c) (i) Open Access

\begin{abstract}
This study focused on the following research objectives: 1) to examine how resilience is related to personal accomplishment of Occupational Therapists; 2) to examine the relationship between personal accomplishment, depersonalization, and emotional exhaustion; 3) to profile Occupational Therapists based on resilience, personal accomplishment, emotional exhaustion, and depersonalization. The sample included 315 Greek Occupational Therapists. Data was collected on resilience (CD-RISC 10), personal accomplishment, emotional exhaustion, and depersonalization (MBI-HSS). A Structural Equation Model (SEM) was successfully specified with the two-step approach to examine how resilience is related to personal accomplishment and how personal accomplishment, emotional exhaustion, and depersonalization interact. The measurement and full SEM model showed a good fit and adequate model-based reliability. The SEM analysis suggested that increased resilience predicted a major increase in personal accomplishment with a standardized direct effect $>0.70, p<0.001$ (49\% explained variance). Additionally, there was a mediation effect of depersonalization in the relationship between personal accomplishment and emotional exhaustion with a significant indirect and total effect, $p<0.001$. Then, Latent Profile Analysis (LPA) followed to describe the Occupational Therapists based on their score on resilience, personal accomplishment, emotional exhaustion, and depersonalization. During the LPA the optimal profile model was selected using an integrative model fit calcula-
\end{abstract}


tion approach based on the Analytic Hierarchy Process (AHP) and 4 profile groups of Occupational Therapists emerged. The scoring patterns of the 4 groups that emerged from PLA suggested that high-resilient Occupational Therapists are at lower burnout risk and low-resilient Occupational Therapists are at higher burnout risk.

\section{Keywords}

Burnout, Resilience, Emotional Exhaustion, Structural Equation Modeling, SEM, Latent Profile Analysis, LPA, Occupational Therapy, Occupational Therapists

\section{Introduction}

In the last twenty years, there was a dramatic increase in the prevalence of burnout in all Western societies (Glasberg, Eriksson, \& Norberg, 2007). Relevant Scholarship argues that occupational therapy is generally a challenging, highly stressful, and burnout-causing health profession (Gupta, Paterson, Lysaght, \& Von Zweck, 2012). This makes occupational therapists (OTs) - like all health professionals-prone to burnout (Lloyd \& King, 2001; Scanlan \& Hazelton, 2019; Sturgess \& Poulsen, 1983).

Why is this a problem? Burnt out OTs are more likely to offer low-quality care or quit their job limiting institutional knowledge, raising training budgets, or discontinuing the therapeutic relationship (Scanlan \& Still, 2013). Furthermore, they can spread burnout and discontentment to peers, contaminating the entire staff (Scanlan, \& Hazelton, 2019). However, OTs "do not choose to burn out" (Schlenz, Guthrie, \& Dudgeon, 1995: p. 986). The prolonged, unrelieved work stress in a highly demanding workplace and the complexity of healthcare expose OTs to burnout (Derakhshanrad, Piven, \& Ghoochani, 2019; Maslach, 1976). However, a unique feature of burnout in comparison to stress is that the social interactions between the OT and the recipient are the major source of stress (Schlenz et al., 1995), and this relevancy to the work environment is one of its major differences from depression (Maslach, Jackson, \& Leiter, 1996).

\subsection{Review of Relevant Scholarship}

Job burnout is the inability to use coping resources in the face of work-related stressful situations, causing a sense of helplessness (Derakhshanrad et al., 2019). Individuals suffering from burnout may also experience diminished personal health resources, recurrent minor health problems, boredom, and inflexibility (Maslach, 1978; Sturgess \& Poulsen, 1983). In the context of occupational therapy burnout is the physical, emotional, and mental exhaustion caused by the loss of OTs' interest in providing the expected healthcare services (Hendrickson, 1979). 
After consistent research results, burnout is described as a syndrome (Maslach, Jackson, \& Leiter, 1996) OTs and all health professionals may commonly experience in response to job stress, developing: 1) emotional exhaustion; 2) depersonalization; and 3) reduced perceived personal accomplishment (Pines \& Maslach, 1978). As a result, burnout OTs emotionally withdraw from previously enjoyable work tasks, lose work meaning and professional effectiveness (Sturgess \& Poulsen, 1983). Emotional exhaustion refers to losing psychological and physical “zest” (Maslach, Jackson, \& Leiter, 1996; Schlenz et al., 1995). Depersonalized OTs no longer show empathy or respect for clients and low personal accomplishment is perceived as low self-appraisal and efficacy regarding work performance (Maslach et al., 1996; Schlenz et al., 1995). Although the three dimensions of the burnout syndrome are discrete, combined they can have cumulative effects, generating gradually more severe symptoms (Reis, Vale, Camacho, Estrela, \& Anjos, 2018). Moreover, the interaction of burnout with personal and organizational resources also moderates the severity of symptoms (Lasalvia, et al., 2009; Lloyd \& King, 2001; Maslach et al., 1996).

In contrast to emotional exhaustion, personal accomplishment is associated with high personal engagement, activation, identification, and absorption (high activation and high identification at the same time; see Demerouti, Mostert \& Bakker, 2010). Engaged OTs are more likely to feel pleasantly tired after a workday than emotionally drained ones (Poulsen, Meredith, Khan, Henderson, Castrisos, \& Khan, 2014). Whereas the mediating effect of external resources between job demands and emotional exhaustion is heavily researched (see Lloyd \& King, 2001), the effect of internal resources is less researched (Derakhshanrad et al., 2019; Schmitt, Zacher, \& Frese, 2012). E.g. the studies on the resilience of OTs are limited. The same is true for studies on the effect of resilience on the personal accomplishment of the OTs. Crucially, resilience is an important internal resource associated with personal accomplishment (Rivard \& Brown, 2019), the positive component of Maslach's burnout model (Maslach et al., 1996).

\subsection{The Professional Resilience of OTs}

The American Psychological Association (2015) defined resilience as the ability to adapt well when facing adversity, trauma, or serious stress. In a similar vein, high resilient OTs can face adversity and use it to thrive and develop personal growth (Rivard \& Brown, 2019). All resilience definitions focus on the ability to bounce back from adversity or stress, adapting successfully (Kyriazos, Stalikas, Prassa, Galanakis, Yotsidi, \& Lakioti, 2018).

Crucially, professional resilience is a learnable internal resource (de Witt, Monareng, Abraham, Koor, \& Saber, 2019; Tugade \& Fredrickson, 2007), promotable through emotion regulation strategies (Tugade \& Fredrickson, 2007). Strategies promoting OTs' resilience include self-reflection, building work-related purpose and meaning, highlighting personal achievements, cultivating professional skills, and acting upon professional values in the face of contextual pressures (McAllister \& McKinnon, 2009). Preserving a personal value system can 
sometimes be challenging but it seems to be effective when dealing with organizational aspects beyond personal control, and can help an OT build professional accomplishment, engagement, and efficacy. Finally, a strong professional identity (Ashby, Ryan, Gray, \& James, 2013) and sense of personal accomplishment (Lloyd \& King, 2001) was reported to protect from burnout, and to build resilience (see Rivard \& Brown, 2019 for more details). Moreover, to cope with burnout, effective coping strategies are setting limits, selecting tasks, balancing homework requirements, managing time to raise effectiveness, receiving social network support, prioritizing, setting goals, and self-care (Gupta et al., 2012). In contrast, in a mixed OT sample from Greece and Cyprus the effect of resilience and organizational factors like working days, years in the current position, quality of relationships with colleagues, holding a managerial position, age and total years of professional experience on burnout levels was limited (Katsiana et al., 2021). Therefore, at an organizational level, policymakers, and health organizations are encouraged to cultivate resilience-building environments and adopt policies and procedures to foster OTs' professional resilience (Rivard \& Brown, 2019). The present study focuses on providing evidence to this end.

\subsection{The Present Study}

The core and essential property of resilience is the ability to bounce back from stress and adversity (Smith, Tooley, Christopher, \& Kay, 2010). On the contrary, the core effect of burnout is the inability to use coping resources in the face of work-related stressful contexts like occupational therapy and healthcare (Derakhshanrad et al., 2019). Some questions that arise are: What is the effect of resilience on personal accomplishment-the positive burnout component-and the other dimensions of burnout? What is the interrelation of the three burnout components that make up this complex burnout mechanism? Could resilient OTs be at low risk of burnout?

Five primary hypotheses arise from the above questions and a causal modeling design was used to test them, by specifying a Structural Equation Model (H1 H5, Figure 1).

H1: Personal Accomplishment has a significant, direct negative effect on Depersonalization ( $p$ ath a).

H2: Depersonalization has a significant, direct positive effect on Emotional Exhaustion (path b).

H3: Persona Accomplishment has a significant, direct negative effect on Emotional Exhaustion (path c).

H4: Resilience has a significant, direct positive effect on Personal Accomplishment (path d).

H5: Depersonalization mediates the relation between Personal Accomplishment and Emotional Exhaustion (path $a{ }^{*} b$ ).

Furthermore, if high-resilient OTs are at less risk of burnout in comparison to low-resilient, then distinct psychological OT profiles are hypothesized to exist. Therefore, two secondary hypotheses arise, and to test them, we carried out a 


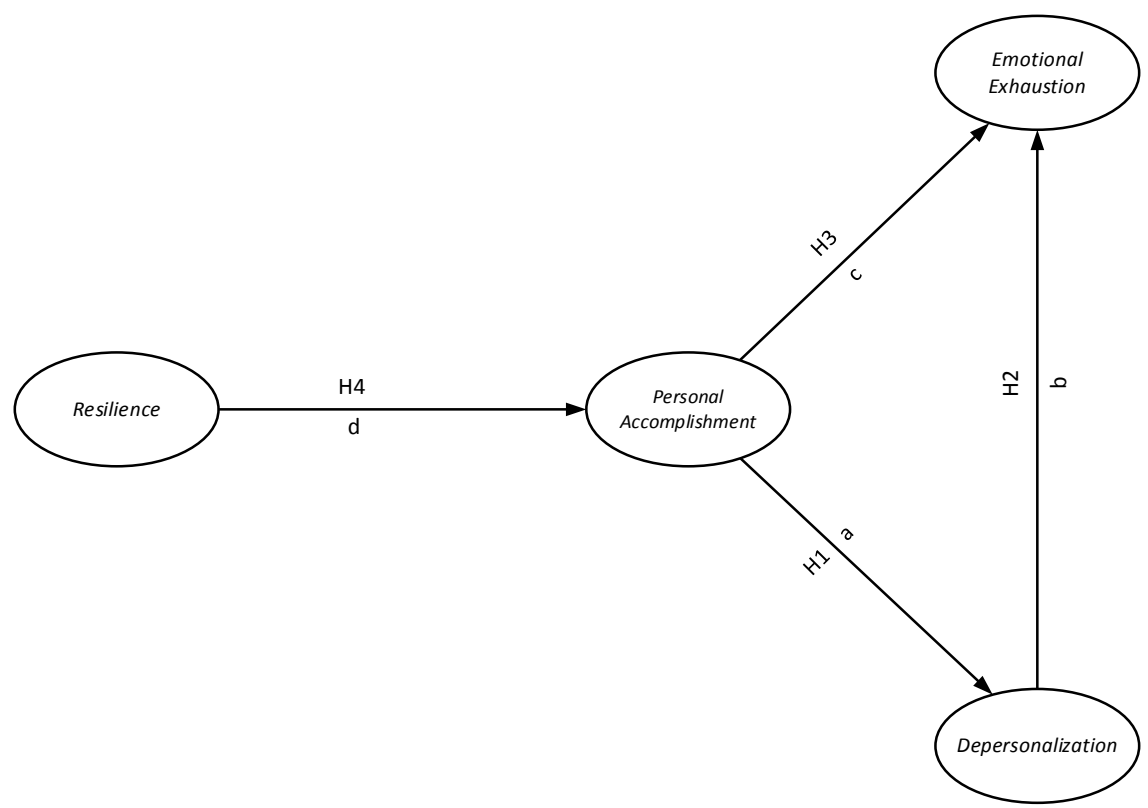

Figure 1. The research model tested with SEM $(\mathrm{N}=315)$. An indirect path (mediation) was also tested $\left(a{ }^{\star} b\right)$.

Latent Profile Analysis (LPA) based on resilience, and burnout (i.e. personal accomplishment, depersonalization, and emotional exhaustion).

H1: OT groups that have high resilience will have low burnout.

H2: OT groups that have low resilience will have high burnout.

\section{Method}

\subsection{Participants}

The inclusion criteria were 1) to be an occupational therapist working in Greece; 2 ) to have at least 6 months of working experience. A total of 315 Greek occupational therapists participated in this study ( $80 \%$ female). They were aged between 21 - 60 years (that is $40 \%$ from 21 - 30 years, 30\% from 31 - 40 years, $20 \%$ from 41 - 50 years, $9 \%$ from 51 - 60 years). Most therapists were married (42\%) or in a permanent relationship (28\%, $27 \%$ unmarried, $3 \%$ other) without children (61\%). Almost 1 in 3 therapists (27\%) had postgraduate qualifications or an additional university degree (13\%). The vast majority of them (76\%) were private health-care workers, in metropolitan areas (75\%), with 1 - 14 years tenure $(80 \%)$ or $\geq 15$ years $(20 \%)$, working mostly with children/teenagers $(84 \%$. $13 \%$ adults, $3 \%$ elderly). This sample was used before (Katsiana et al., 2021).

\subsection{Procedure}

Respondents were involved in the study with voluntary response sampling. Specifically, the registered members of the Panhellenic Occupational Therapists Association $(N=700)$ received an email inviting them to participate. Respondents received no inducement to participate. The study was available online from November 2019 to March 2020. Three hundred and forty-five voluntarily 
took the online survey (response rate 49\%). In March 2020 Greece entered a lockdown period to control the COVID-19 pandemic and the survey was discontinued to avoid response bias because the achieved subjects per variable ratio for the two measuring instruments combined $(=9.8)$ was sufficient for robust SEM model parameters (Schumacker \& Lomax, 2015: p. 39). Note that a response rate of $49 \%$ is good for an on-line survey, with the average return rate of online surveys on convenience samples being 33\% (Nulty, 2008). The response rate of some OT surveys was comparable, i.e. 40.5\% (Poulsen et al., 2014), 42\% (Derakhshanrad et al., 2019), or 50\% (Devery, Scanlan, \& Ross, 2018).

\section{Sample Size, Power, and Precision}

Thirty cases were excluded for not meeting the inclusion criteria (they did not work in Greece) leaving a final sample of $N=315$. A priori power analysis based on population RMSEA of the full SEM model (MacCallum, Browne, \& Sugawara, 1996), suggested that a sample size of $N=72(<N=315)$ was necessary for achieving a power of about $80 \%$ to reject a wrong model $(d f=457)$ with an amount of misspecification corresponding to RMSEA $=0.05$ on alpha $=0.05$.

\subsection{Measures}

Maslach Burnout Inventory-Human Services Survey(MBI-HSS; Maslach Jackson, \& Leiter, 1996).

The MBI is a 22-item self-assessment questionnaire measuring perceived burnout with 22 items (e.g. "I feel burned out from my work") The items are rated on a 7-point frequency scale (from $0=$ Never to $6=$ Every Day). MBI-HSS evaluates the 3 facets of the burnout syndrome in 3 factors: Emotional Exhaustion (EE; 9 items), Depersonalization (DP; 5 items), and Personal Accomplishment (PA; 8 items). The items for each factor are aggregated separately to generate 3 scores, one for each factor-where a high EE score indicates high Burnout, a high DP score indicates high Burnout and a high PA score indicates low Burnout. Each score is coded as low, average, or high by using the numerical cutoff points (Maslach, Jackson, \& Leiter, 1996). Maslach et al. reported internal consistency reliability of $\alpha=0.90$ (EE), 0.79 (DP), and 0.71 (PA). The Greek version of MBI-HSS was used in this study (Galanakis, Moraitou, Garivaldis, \& Stalikas, 2009; Kokkinos, 2006).

Connor-Davidson Resilience Scale, 10-item version (CD-RISC 10; Campbell-Sills, \& Stein, 2007; Connor \& Davidson, 2003)

This is a short version of the original CD-RISC (Connor \& Davidson, 2003). It is a self-report, unidimensional measure of resilience with 10 items (e.g. "Coping with stress can strengthen me") rated on 5-point Likert scale ( $0=$ Not True at All; $4=$ True Nearly All of The Time). The higher the score, the higher the perceived resilience. The scale internal consistency reliability in a Spanish sample was $\alpha=0.85$ (Notario-Pacheco et al., 2011).

Data collected for some additional variables (like peer relationships) were not used in the present study. 


\subsection{Data Diagnostics}

The fields of the online survey form were set as required to eliminate missing values. Outliers were detected separately for each study measure and for the SEM measurement model too using the Mahalanobis distance criterion. Multivariate normality of the burnout and resilience scale scores was examined using Mardia's multivariate kurtosis and skewness test, Henze-Zirkler's consistent test, Doornik-Hansen omnibus test, and Energy test. Only multivariate normality tests were evaluated. A normal multivariate distribution, suggests that each data variable has also a normal univariate and bivariate distribution (Wang \& Wang, 2020).

\subsection{Analytic Strategy}

Initially, a CFA confirmed the factor structure of MBI-HSS and CD-RISC 10 separately, to ensure that the hypothesized structure was tenable in this special population of OTs because MBI-HSS structure was previously verified on different, special populations (Galanakis et al., 2009; Kokkinos, 2006), and CD-RISC 10 was unverified.

Next, a Structural Equation Model (SEM) was specified with the latent variables of EE, DP, PA, and resilience to test the study's main hypotheses. The SEM measurement and the full SEM model (Byrne, 2012) were evaluated (two-Step Approach; Anderson \& Gerbing, 1988). We estimated all models with a robust estimator (MLR) to correct the chi-square and standard errors for non-normality. Model fit criteria (Hu \& Bentler, 1999) were RMSEA [90\% CI $\leq$ $0.06] \leq 0.06$, SRMR $\leq 0.08, \mathrm{CFI} \geq 0.95$, TLI $\geq 0.95$. A priori and post hoc power analysis evaluated the sample size adequacy of the full SEM model with the population the RMSEA (MacCallum, Browne, \& Sugawara, 1996), with an alpha level of 0.05. Internal consistency reliability of all measures was evaluated with Cronbach's alpha [95\% CI] (Feldt, Woodru, \& Salih, 1987) and model-based reliability with Omega coefficient (McDonald, 1999).

Then a Latent Profile Analysis (LPA) followed to classify the sample based on their scores on EE, DP, PA, and resilience. LPA is a model-based approach that classifies individuals into distinct groups (i.e. latent profiles) based on their scores on a set of continuous observed variables by using statistical tests and model fit indicators to identify the number of profiles (see Masyn, 2013). It differs from Latent Class Analysis (LCA) which clusters categorically observed variable sets (Wang \& Wang, 2020). For comparisons between the latent profile models, we used the following model fit indicators: the mean probability for maximum profile membership likelihood (entropy; Ramaswamy, DeSarbo, Reibstein, \& Robinson, 1993), Akaike Information Criterion (AIC), Bayesian Information Criterion (BIC), and Bootstrapped Likelihood Ratio Test (BLRT). For deciding on the optimal profile model to be retained we implemented the calculation proposed by Akogul and Erisoglu (2017) integrates several fit indices to choose the optimal profile model using the Analytic Hierarchy Process (AHP; 
Saaty, 1990). Data were analyzed with $\mathrm{R}$ version 4.0.2. (R Development Core Team, 2020), with the packages "tidyLPA" (Rosenberg, Beymer, Anderson, Van Lissa, \& Schmidt, 2018), "lavaan" (Rosseel, 2012), and "semPlot" (Epskamp, 2019). See all the steps of the analytic strategy listed in Table 1.

\section{Results}

\subsection{Preliminary Analysis}

There were no missing values. We examined MBI-HSS, CD-RISC10 and the measurement model for multivariate normality and outliers (Table 2). Multivariate skewness, kurtosis, and all other tests were statistically significant ( $p<$ 0.001). Outliers (Table 2) were not inaccurate data entries and did not weaken findings (see Kyriazos, 2018). Therefore, they were not removed $(N=315)$.

Subsequently, a CFA confirmed the factor structure of MBI-HSS and CD-RISC 10 separately to ensure there were no misspecifications in the SEM measurement

Table 1. An overview of the study analyses.

\begin{tabular}{|c|c|c|}
\hline Analysis & Description & Rationale \\
\hline 1 & Multivariate Normality Test & $\begin{array}{l}\text { To test for the multivariate normality assumption with } \\
\text { Mardia's multivariate kurtosis and skewness, } \\
\text { Henze-Zirkler's consistent test, Doornik-Hansen } \\
\text { omnibus test, and Energy test. }\end{array}$ \\
\hline 2 & Detecting outliers & To detect outliers with Mahalanobis distance. \\
\hline 3 & CFA on each study measures & $\begin{array}{l}\text { To confirm the factor structure of MBI-HSS and } \\
\text { CD-RISC } 10 \text { in this special Greek population (OTs), } \\
\text { ensuring no misspecifications in the SEM model. }\end{array}$ \\
\hline 4 & $\begin{array}{l}\text { Cronbach's alpha \& McDonald's } \\
\text { omega (1999) }\end{array}$ & $\begin{array}{l}\text { To calculate the internal consistency reliability and the } \\
\text { model-based reliability of MBI-HSS and CD-RISC 10, } \\
\text { before the SEM measurement model with } \omega \text { t coefficient } \\
\text { (McDonald, 1999). }\end{array}$ \\
\hline 5 & $\begin{array}{l}\text { Spearman rho Correlations, and } \\
\text { means }\end{array}$ & Descriptive statistics and burnout scores. \\
\hline 6 & $\begin{array}{l}\text { Test the SEM measurement } \\
\text { model and model-based } \\
\text { reliability }\end{array}$ & $\begin{array}{l}\text { To evaluate the measurement model fit with a CFA and } \\
\text { to evaluate reliability of the measurement variables and } \\
\text { the reliability latent variables with } \omega t \text { coefficient } \\
\text { (McDonald, 1999). }\end{array}$ \\
\hline 7 & Test the full SEM model fit & To evaluate if the structural model fit is adequate. \\
\hline 8 & $\begin{array}{l}\text { A priori \& post hoc power } \\
\text { analysis of the full SEM model }\end{array}$ & $\begin{array}{l}\text { To calculate the required sample for achieving a power } \\
\text { of } 80 \% \text { to reject a wrong model. An alpha level of } 0.05 \\
\text { was assumed with an RMSEA misspecification of } 0.05 \\
\text { (MacCallum, Browne, \& Sugawara, 1996). }\end{array}$ \\
\hline 9 & $\begin{array}{l}\text { Primary Hypotheses testing } \\
\text { (Primary hypotheses H1 - H5) }\end{array}$ & $\begin{array}{l}\text { To test the hypothesized relationships between } 4 \text { latent } \\
\text { variables with } 4 \text { direct associations, and } 1 \text { mediation. } \\
\text { No covariates were used. }\end{array}$ \\
\hline 10 & $\begin{array}{l}\text { Latent Profile Analysis (LPA) } \\
\text { (Secondary Hypotheses H1 - H2) }\end{array}$ & $\begin{array}{l}\text { Use the scores of the latent variables of the SEM model } \\
\text { to profile the sample and check if the profiles that } \\
\text { emerged confirm the hypotheses tested with the SEM } \\
\text { model. }\end{array}$ \\
\hline
\end{tabular}


Table 2. Multivariate normality tests, outliers and critical value for Mahalanobis distance $\left(\chi^{2}\right)$ for each study measure and for the measurement model, $(N=315)$.

\begin{tabular}{cccccccc}
\hline Measure & Outliers & $D^{2}$ C.V. $\chi^{2}(d f)^{*}$ & $\begin{array}{c}\text { Mardia’s } \\
\text { Skew }\end{array}$ & $\begin{array}{c}\text { Mardia’s } \\
\text { Kurtosis }^{*}\end{array}$ & Doornik-Hansen $(d f)^{*}$ & Energy Test $^{*}$ & Henze-Zirkler $^{*}$ \\
\hline MBI-HSS $(k=22)$ & 12 & $48.27(22)$ & 5294.88 & 30.52 & $245.199(44)$ & 6.31 & 1.22 \\
CD-RISC10 $(k=10)$ & 6 & $29.59(10)$ & 495.97 & 11.05 & $60.07(20)$ & 2.41 & 1.10 \\
Measurement Model $(k=22)$ & 11 & $62.49(32)$ & $10,504.41$ & 29.06 & $275.30(64)$ & 4.70 & 1.02 \\
\hline
\end{tabular}

${ }^{*} p<0.001$.

model. The model fit for the 3-factor MBI-HSS model (Maslach et al., 1996) was adequate, $\chi^{2}(203)=403.19, p=0.000, \mathrm{CFI}=0.929, \mathrm{TLI}=0.920, \mathrm{RMSEA}=0.056$ $90 \%$ CI $[0.048,0.064]$, SRMR $=0.079$ with 3 residual covariances added (between PA items 4 and 7, PA items 7 and 9, and DP items 10 and 11). Loadings ranged from 0.332 to 0.920 and the inter-factor correlations from $|0.41|$ to $|0.48|$. More specifically, the correlation between DP and PA was (as expected) negative $(-0.41)$ and between DP and EE positive (0.48). Equally, the correlation between $\mathrm{PA}$ and EE was negative $(-0.44)$. The internal consistency reliability of this solution was $\alpha=0.9295 \%$ CI $[0.91,0.94]$ (EE), $\alpha=0.7095 \%$ CI [0.65, 0.75] (DP), $\alpha$ $=0.8195 \% \mathrm{CI}[0.78,0.84](\mathrm{PA})$. And the model-based reliability based on McDonald's $\omega$ was $\omega=0.93$ (EE), 0.61 (DP) and 0.77 (PA). This is the original 3 -factor structure of the MBI-HSS postulated by Maslach et al. (1996) and confirmed with CFA by Boles et al. (2000).

The unidimensional structure of CD-RISC10 (Campbell-Sills \& Stein, 2007) had a good model fit, $\chi^{2}(35)=70.62, p=0.001$, CFI $=0.947$, TLI $=0.931$, RMSEA $=0.05790 \%$ CI $[0.039,0.075]$, SRMR $=0.048$. Loadings ranged from $0.408-0.704, \alpha=0.8395 \%$ CI $[0.80,0.85]$, and McDonald's $\omega=0.83$. The unidimensional structure of CD-RISC 10 (Campbell-Sills \& Stein, 2007) is easier to handle in an SEM model and it was preferred over the original (Connor \& Davidson, 2003).

\subsection{Descriptive Statistics}

Table 3 displays the raw correlations and means of MBI-HSS and CD-RISC10 scores. Cutoffs outlined in the MBI test manual suggested that the OTs in this sample experienced average EE levels, low DP levels, and average PA levels.

\subsection{The SEM Measurement Model}

The measurement model had four latent variables (resilience, PA, DP, and EE) and 32 observed variables and it showed a good model fit, $\chi^{2}(455)=806.00, p=$ $0.000, \mathrm{CFI}=0.909, \mathrm{TLI}=0.900, \mathrm{RMSEA}=0.04990 \% \mathrm{CI}[0.044,0.055], \mathrm{SRMR}=$ 0.072 (MLR estimator). The standardized factor loadings remained above the 0.40 threshold (Brown, 2015), ranging from 0.406 to 0.812 , and they were higher on their assigned latent variable than on the other latent variables of the measurement model. Also, all the 32 observed variables significantly loaded on their latent variable, suggesting robustness (Table 4). Omega coefficient (McDonald, 
Table 3. Descriptive statistics and raw correlations (Spearman rho) for the CD-RISC10 and MBI-HSS Scores.

\begin{tabular}{|c|c|c|c|c|c|c|}
\hline Measures & $M$ & $S D$ & 1 & 2 & 3 & 4 \\
\hline 1. CD-RISC10 & 26.83 & 0.49 & - & & & \\
\hline 2. MBI-HSS EE & 19.76 & 0.62 & $-0.39^{\star *}$ & - & & \\
\hline 3. MBI-HSS DP & 5.09 & 0.27 & $-0.18^{\star *}$ & $0.41^{\star \star}$ & - & \\
\hline 4. MBI-HSS PA & 38.85 & 0.47 & $0.58^{\star \star}$ & $-0.35^{\star \star}$ & $-0.28^{\star *}$ & - \\
\hline
\end{tabular}

$\mathrm{DP}=$ Depersonalization, $\mathrm{PA}=$ Personal Accomplishment, $\mathrm{EE}=$ Emotional Exhaustion. ${ }^{* *} p<0.01$.

Table 4. Standardized loadings $(\lambda)$, and R squared for the SEM measurement model $(N=$ 315).

\begin{tabular}{lccccccc}
\hline \multirow{2}{*}{ Latent Variable } & $\begin{array}{c}\text { Observed } \\
\text { Variable }\end{array}$ & $\lambda^{*}$ & $\mathrm{R}^{2}$ & Latent Variable & $\begin{array}{c}\text { Observed } \\
\text { Variable }\end{array}$ & $\lambda^{*}$ & $\mathrm{R}^{2}$ \\
\hline MBI-HSS DP & DP5 & 0.594 & 0.353 & EE6 & 0.744 & 0.554 \\
& DP10 & 0.559 & 0.312 & EE8 & 0.92 & 0.846 \\
& DP11 & 0.513 & 0.263 & EE13 & 0.747 & 0.558 \\
& DP15 & 0.648 & 0.420 & EE14 & 0.526 & 0.277 \\
& DP22 & 0.428 & 0.183 & EE16 & 0.729 & 0.531 \\
& PA4 & 0.353 & 0.125 & EE20 & 0.793 & 0.629 \\
& PA7 & 0.507 & 0.257 & CD-RISC 10 & CDRISC 1 & 0.493 & 0.243 \\
& PA9 & 0.61 & 0.372 & CDRISC2 & 0.646 & 0.417 \\
& PA12 & 0.718 & 0.516 & CDRISC3 & 0.547 & 0.299 \\
& PA17 & 0.607 & 0.368 & CDRISC4 & 0.425 & 0.181 \\
& PA18 & 0.672 & 0.452 & CDRISC5 & 0.564 & 0.318 \\
& PA19 & 0.596 & 0.355 & CDRISC6 & 0.516 & 0.266 \\
& PA21 & 0.611 & 0.373 & CDRISC7 & 0.508 & 0.258 \\
& EE1 & 0.852 & 0.726 & CDRISC8 & 0.713 & 0.508 \\
& EE2 & 0.74 & 0.548 & CDRISC9 & 0.672 & 0.452 \\
& EE3 & 0.848 & 0.719 & 0.661 & 0.437 \\
\hline
\end{tabular}

Note. $\mathrm{DP}=$ Depersonalization, $\mathrm{PA}=$ Personal Accomplishment, EE = Emotional Exhaustion, Model Estimator $=$ MLR. ${ }^{*} p<0.001$.

1999) for each latent variable was $\omega=0.93(\mathrm{EE}), 0.78(\mathrm{PA}), 0.61(\mathrm{DP})$ and 0.83 (CD-RISC 10), suggesting adequate model-based reliability (Kline, 2016; Kyriazos 2017a). The $\mathrm{R}^{2}$ ranged from 0.125 to 0.846 , i.e. the latent variables accounted for a variance from $13 \%$ to $85 \%$ by each observed variable (Table 4 ). The interfactor correlations of the measurement model were in the expected directions, ranging from $|0.24|$ to $|0.69|$. More specifically, the interfactor correlations of resilience (CD-RISC) with DP, PA, and EE were $-0.24,0.692$, and -0.41 respectively. The interfactor correlation of DP with PA was -0.42 , and DP with EE 0.48. Equally, the intercorrelation of PA with EE was -0.43 . 


\subsection{The Full SEM Model}

The full SEM model to study the relationship of resilience and personal accomplishment, emotional exhaustion and depersonalization showed a god fit, $\chi^{2}$ $(457)=812.54, p=0.000, \mathrm{CFI}=0.908, \mathrm{TLI}=0.900, \mathrm{RMSEA}=0.05090 \% \mathrm{CI}$ [0.044, 0.055], SRMR $=0.075$.

Post-hoc power analysis based on population the RMSEA of the full SEM model (MacCallum, Browne, \& Sugawara, 1996) suggested that $N=315$ was associated with $>99.99 \%$ power to reject a wrong model ( $d f=457$, RMSEA $=0.05$ on alpha 0.05 ).

\section{Hypotheses testing (Primary hypotheses H1 - H5)}

The structural results for the relationship of resilience (CD-RISC 10), and PA, EE, and DP are presented in Table 5 (path coefficients and their 95\% CI) and in Figure 2 (structural model). Standardized path coefficients (Table 5) showed

Table 5. Structural results for the primary hypotheses $\mathrm{H} 1$ - H4 regarding the direct effects in the full SEM model $(N=315)$.

\begin{tabular}{|c|c|c|c|c|c|c|c|c|c|}
\hline \multirow{2}{*}{$\mathrm{H}$ (path) } & \multirow{2}{*}{ Path Description } & \multirow{2}{*}{$\beta$} & \multirow{2}{*}{$B$} & \multicolumn{2}{|c|}{$95 \%$ CI for B } & \multirow{2}{*}{$S E$} & \multirow{2}{*}{$z$} & \multirow{2}{*}{$P$} & \multirow{2}{*}{$\mathrm{A} / \mathrm{R}$} \\
\hline & & & & LL & LU & & & & \\
\hline H1 (a) & $\mathrm{PA} \rightarrow \mathrm{DP}$ & -0.405 & -0.686 & -1.067 & -0.306 & 0.194 & -3.534 & 0.000 & A \\
\hline $\mathrm{H} 2(\mathrm{~b})$ & $\mathrm{DP} \rightarrow \mathrm{EE}$ & 0.348 & 0.588 & 0.287 & 0.889 & 0.154 & 3.826 & 0.000 & A \\
\hline $\mathrm{H} 3(\mathrm{c})$ & $\mathrm{PA} \rightarrow \mathrm{EE}$ & -0.328 & -0.941 & -1.664 & -0.217 & 0.369 & -2.547 & 0.011 & A \\
\hline $\mathrm{H} 4$ (d) & CD-RISC $10 \rightarrow$ PA & 0.701 & 0.872 & 0.470 & 1.275 & 0.205 & 4.250 & 0.000 & A \\
\hline
\end{tabular}

Note. $\mathrm{CI}=$ Confidence Interval, $\mathrm{LL}=$ Lower Limit, $\mathrm{UL}=$ Upper Limit, $\mathrm{z}=\mathrm{z}$-value, $\mathrm{DP}=$ Depersonalization, $\mathrm{PA}=$ Personal Accomplishment, $\mathrm{EE}=$ Emotional Exhaustion, $\mathrm{H}=$ Hypothesis, $\mathrm{A}=$ Hypothesis Accepted, $\mathrm{R}$ $=$ Hypothesis Rejected, Model Estimator $=$ MLR.

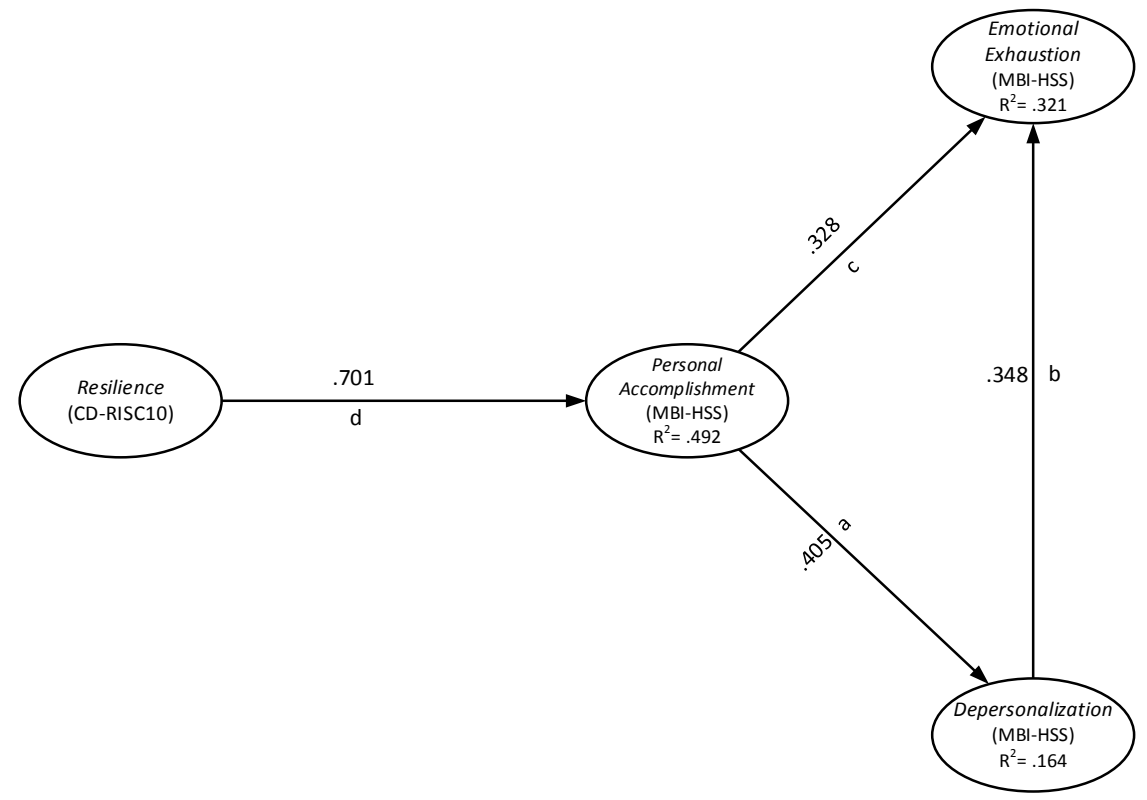

Figure 2. The path diagram of the SEM structural model (standardized coefficients, all $p$ $<0.001)$. 
that resilience had a significant positive effect on PA ( $\beta=0.701, p<0.001), 49 \%$ explained variance (see all the explained variances in Figure 2). The effect of PA on EE was significantly mediated by DP, total effect $=-0.981$, and indirect effect $=-0.141$ (Table 6$)$.

See the full SEM model in Figure A1 of the Appendix.

\subsection{Latent Profile Analysis (LPA; Secondary Hypotheses H1 - H2)}

Then, LPA followed to group the OTs based on their scores on resilience, EE, DP, and PA, i.e. the latent constructs of the SEM model. EE, DP, PA and CD-RISC 10 scores were scaled (z scores; $M=0 ; S D=1$ ) to make them comparable before profile estimation. We compared 4 profile models with different variance-covariance specifications. Model 1 had equal variances and covariances fixed to zero. Model 2 had varying variances and covariances fixed to zero. Model 3 had equal variances and equal covariances and Model 4 had varying variances and varying covariances. For each model specification, profiles with 1 - 4 groups were tested (a total of 16 group solutions). Model fit comparison based on the integrative function of multiple fit indicators (Akogul \& Erisoglu, 2017; Saaty, 1990) suggested that Model 2 (varying variances and covariances fixed to zero) with 4 groups was the optimal solution. The model fit for each solution is listed in Table 7.

The OTs in Group 4 had the highest resilience scores, the lowest EE and DP scores combined with the highest PA scores (presented with the line connecting the cross symbol across bars). Group 3 had the second-highest resilience scores, the second-lowest EE and DP scores, and the second-highest PA scores (presented with the line connecting the square symbol across bars). Group 2 had the lowest resilience scores of all groups, the highest EE scores, equally high DP scores with Group 1, and the lowest PA scores (presented with the line connecting the triangle symbol across bars). Group 1 had the third-highest resilience scores, the second-highest EE, and equally high DP scores with Group 2 and equally high PA scores with Group 3 (presented with the line connecting the circle symbol across bars). Figure 3 contains a plot with the 4 distinct OTs' profiles based on their resilience, EE, DP and PA.

Table 6. Indirect and total effects of personal accomplishment on emotional exhaustion through depersonalization in the full SEM model $(N=315)$.

\begin{tabular}{cccccccc}
\hline \multirow{2}{*}{ Effect $(\mathrm{path})$} & Estimate & \multicolumn{2}{c}{$95 \% \mathrm{CI}$ for B } & & & \\
\cline { 3 - 6 } & & $\mathrm{LL}$ & $\mathrm{LU}$ & & & & \\
& & & & & & \\
\hline Indirect $=(\mathrm{a} * \mathrm{~b})$ & -0.141 & -0.639 & -0.168 & 0.120 & -3.362 & 0.000 & -0.205 \\
TOTAL $=\mathrm{c}+(\mathrm{a} * \mathrm{~b})$ & -0.981 & -1.344 & -0.618 & 0.185 & -5.295 & 0.000 & -0.310 \\
\hline
\end{tabular}

Note. $\mathrm{CI}=$ Confidence Interval, $\mathrm{LL}=$ Lower Limit, $\mathrm{UL}=$ Upper Limit, Estimator $=\mathrm{MLR} . \mathrm{z}=\mathrm{z}$-value $=$ Wald statistic, $p(>|\mathrm{z}|)=p$ value for testing that the parameter equals zero in the population (H0), $\operatorname{Std}_{A L L}=$ Solution standardizes the factor loadings by the $S D$ of both the predictor and the outcome. 
Table 7. Model fit statistics for the 1 to 4 profiles solutions estimated with 1 - 4 groups each based on the EE, DP, PA and resilience scores of the OTs to test secondary hypotheses $\mathrm{H} 1$ - H2 secondary hypotheses $\mathrm{H} 1-\mathrm{H} 2(N=315)$.

\begin{tabular}{cccccccc}
\hline Model & Groups & AIC & BIC & Entropy & $n$ min & $n$ max & BLRT $p$ \\
\hline 1 & 1 & 3587.72 & 3617.74 & 1 & 1 & 1 & \\
1 & 2 & 3398.08 & 3446.87 & 0.72 & 0.37 & 0.63 & 0.01 \\
1 & 3 & 3358.77 & 3426.31 & 0.71 & 0.15 & 0.44 & 0.01 \\
1 & 4 & 3312.65 & 3398.96 & 0.72 & 0.12 & 0.42 & 0.01 \\
2 & 1 & 3587.72 & 3617.74 & 1 & 1 & 1 & \\
2 & 2 & 3323.43 & 3387.22 & 0.73 & 0.45 & 0.55 & 0.01 \\
2 & 3 & 3239.68 & 3337.25 & 0.74 & 0.15 & 0.51 & 0.01 \\
2 & 4 & 3197.61 & 3328.95 & 0.74 & 0.09 & 0.33 & 0.01 \\
3 & 1 & 3351.93 & 3404.46 & 1 & 1 & 1 & \\
3 & 2 & 3312.58 & 3383.88 & 0.8 & 0.24 & 0.76 & 0.01 \\
3 & 3 & 3280.37 & 3370.43 & 0.81 & 0.08 & 0.71 & 0.01 \\
3 & 4 & 3290.53 & 3399.36 & 0.55 & 0.09 & 0.43 & 0.97 \\
4 & 1 & 3351.93 & 3404.46 & 1 & 1 & 1 & \\
4 & 2 & 3234.11 & 3342.94 & 0.73 & 0.32 & 0.68 & 0.01 \\
4 & 3 & 3199.04 & 3364.15 & 0.73 & 0.12 & 0.53 & 0.02 \\
4 & 4 & 3180.64 & 3402.04 & 0.77 & 0.09 & 0.48 & 0.06 \\
\hline
\end{tabular}

Note. AIC $=$ Akaike Information Criterion, BIC $=$ Bayesian Information Criterion, BLRT $=$ Bootstrapped Likelihood Ratio Test. Bold typeface indicates the best model.

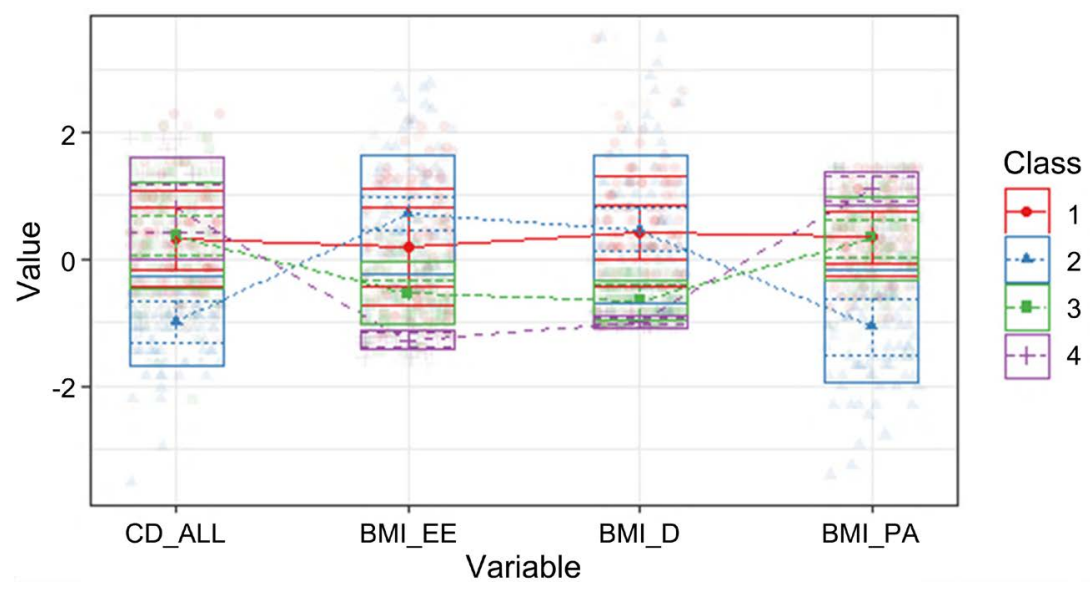

Figure 3. The 4 groups of the optimal profile model (Model 2) based on the EE, DP, PA and resilience scores of the OTs $(N=315)$. Note. Bars indicate the confidence interval for the group centroids; Each bar indicates the $S D$ within each group, incorporating $+/-64 \%$ of the cases in a normal distribution; Each raw datapoint becomes most visible for the group with the highest membership probability, i.e. data transparency is weighted by the posterior group probability.

\section{Discussion}

The purpose of this study was: 1) to test the effect of resilience on personal ac- 
complishment and the inter-relation between personal accomplishment, emotional exhaustion, and depersonalization with an SEM model and 2) to test if distinct psychological profiles of Occupational Therapists emerge based on resilience, personal accomplishment, emotional exhaustion and depersonalization by profiling OTs with Latent Profile Analysis (LPA). All primary and secondary research hypotheses tested with SEM and LPA respectively were confirmed.

For the interpretation of the SEM model results, for standardized direct effects Kline (2016) suggested that standardized direct effects are small when they are less than 0.10, medium when they are around 0.30, and large when they are around 0.50 Adopting Kline's criteria, the estimates of the SEM model suggested that increased PA predicted decreased EE with a moderate-large standardized direct effect. Increased DP predicted an increase in EE of a moderate magnitude. In contrast, increased personal accomplishment predicted a decrease in EE with a moderate standardized direct effect. Lastly and most importantly, an increase in resilience predicted a major increase in PA with a standardized major direct effect $>0.70$. Alternative SEM models with direct paths from resilience to depersonalization and emotional exhaustion had an unacceptable model fit and they were not retained. The same was true for models tested with all the work-related demographic variables of the sample.

Generally, the tripartite model of burnout used is well documented in OT literature, postulating that healthcare professionals like OTs experience chronic work-related stress (Maslach, 1993): EE, DP (i.e. cynicism), and low PA. Therefore, the negative relationship of PA with DP and EE is well-documented (Maslach et al., 1996; Lloyd \& King, 2004). However, findings from structural models proposed that PA was unrelated to EE, rather they were reported to move in parallel (Maslach et al., 1996).

A sense of accomplishment (competence) was reported to work separately from EE, as a protective factor (Lloyd \& King, 2004), confirming the results of this study. Interestingly, resilience explains half of the variance of PA with a very strong, significant positive effect. PA of OTs contributes to resilience and effective coping strategies (Sweeney, Nichols, \& Cormack, 1993; Lloyd \& King, 2001), confirming our findings. Actually, OT literature proposed that OT students can counterbalance stress and burnout by building professional resilience and self-care (de Witt et al., 2019). However, according to our findings, PA was related to EE through the significant mediation of DP. Relevant literature suggests that OTs may become depersonalized and detached, in an effort to protect themselves from EE, and they contact less and more distantly with their recipients, becoming more needlessly bureaucratic (Maslach, 1976; Sturgess \& Poulsen, 1983).

Furthermore, distinct psychological profiles of Occupational Therapists were hypothesized (secondary hypotheses) based on resilience, personal accomplishment, emotional exhaustion, and depersonalization: 1) OT groups with high resilience and low burnout and 2) OT groups with low resilience and high burnout. These secondary, exploratory hypotheses were evaluated with a Latent 
Profile Analysis (LPA). This could answer the question whether high-resilient OTs are at lower risk of emotional exhaustion and depersonalization, and have increased personal accomplishment than low-resilient OTs-as the SEM model implicitly suggested.

Four groups emerged that directly demonstrate that high-resilient OTs have less emotional exhaustion and depersonalization and higher personal accomplishment in comparison to low-resilient OTs. Specifically, the OTs in Group 4 were the most resilient, and they experienced the lowest emotional exhaustion and depersonalization along with the highest personal accomplishment. The OTs of Group 3, showed an identical pattern. They were the second most resilient and they experienced the second-lowest emotional exhaustion and depersonalization and the second-highest personal accomplishment. Group 2 showed the inverse pattern. They were the least resilient of all groups, and they experienced the highest emotional exhaustion, equally high depersonalization, and the lowest personal accomplishment. OTs in Group 1 had all scores above and below average. They ranked third in resilience, second in emotional exhaustion, and as highly depersonalized with OTs of Group 1 but as high personal accomplishment of OTs in Group 3. In sum, Groups 4, and 2 confirmed the secondary hypotheses that resilient OTs are at low burnout risk and that low resilient OTs are at high burnout risk. OTs in Group 1 experience average burnout and low resilience. Unfortunately, no similar LPA studies exist to compare these findings.

\section{Implications \& Limitations}

The generalizability of the findings is relatively safe to make due to their statistical validity (see Kyriazos, 2017b). That is, the SEM research model to study the relationships between resilience, personal accomplishment, emotional exhaustion, and depersonalization showed a good fit, robust loadings, highly significant effects and power analysis indicated enough sample size. The same was true for the LPA analysis, which strengthened the SEM results.

Interpretation of the findings however should be made cautiously because the voluntary response sampling is a non-probability sampling method, similar to ad hoc samples. Furthermore, cross-cultural comparisons are a challenge because OT literature has unique variability due to differences in OT specializations, in MBI measures used (HSS, GS, etc.), and wide differences in healthcare settings and other work-related factors. However, the response rate was satisfactory, comparable to similar studies, and the sampling frame very narrow permitting safe interpretation of the results.

One of the study limitations was the imbalanced sample in terms of gender. Another limitation was that the study was disrupted by the early COVID-19 quarantine, so the initial response to the quarantine may have some sort of impact (if any). Lastly, the cross-sectional, design of this study cannot permit causal inference (Stalikas \& Kyriazos, 2019). Causal inference is a matter of study design (Kline, 2020), although this rigid view on causality with SEM can be somewhat 
problematic (Bollen \& Pearl, 2013; Kline, 2020). Future research could explore if resilience of OTs is associated to a number of positive work-related constructs like flow (for Greece see Kyriazos, Stalikas, Prassa, Galanakis, Flora \& Chatzilia, 2018), hope (for Greece see Yotsidi, Pagoulatou, Kyriazos, \& Stalikas, 2018), flourishing (for Greece see Kyriazos, Stalikas, Prassa, Yotsidi, Galanakis, \& Pezirkianidis, 2018) and life meaning (for Greece see Stalikas, Kyriazos, Yotsidi, Prassa, 2018). However, personal and family relationships may also affect OTs' resilience therefore, another future research possibility could be to explore the association of OTs' resilience to constructs like interpersonal anxiety (for Greece see Giotsa, Kyriazos, \& Mitrogiorgou, 2018; Kyriazos \& Giotsa, 2019) or family-related constructs like parental behaviors (for Greece see Kyriazos \& Stalikas, 2019a) and positive parenting (for Greece see Kyriazos \& Stalikas, 2018; Kyriazos \& Stalikas, 2019b).

\section{Conclusion}

This work hopefully offers useful insights into the effect of resilience in mitigating the vulnerability of the OTs to burnout, providing a base for more models of resilience, the burnout mechanism, and effective coping of OTs (Gupta et al., 2012), or OT students (de Witt et al., 2019) because resilience is a learnable resource (Tugade \& Fredrickson, 2007).

Moreover, it extends the current research on the interaction of PA with resilience and other well-being constructs like work satisfaction (Devery et al., 2018; Scanlan \& Still, 2013) flow and work engagement, or problem-solving and creativity (Derakhshanrad et al., 2019). By focusing more on the interaction of PA with DP and EE and the mediating role of DP between PA and EE more evidence is available to inform evidenced-based prevention and intervention strategies, offering more tools for policymakers and relevant organizations to build effective interventions that can boost resilience, and effective coping of OTs and OT students.

Finally, this study implements a new hybrid research cycle containing both SEM and LPA, two powerful techniques that effectively corroborate one-another.

\section{Conflicts of Interest}

The authors declare no conflicts of interest regarding the publication of this paper.

\section{References}

Akogul, S., \& Erisoglu, M. (2017). An Approach for Determining the Number of Clusters in a Model-Based Cluster Analysis. Entropy, 19, 452. https://doi.org/10.3390/e19090452

American Psychological Association (2015). The Road to Resilience. https://www.apa.org/topics/resilience

Anderson, J. C., \& Gerbing, D. W. (1988). Structural Equation Modeling in Practice: A Review and Recommended Two-Step Approach. Psychological Bulletin, 103, 411-423. 
https://doi.org/10.1037/0033-2909.103.3.411

Ashby, S. E., Ryan, S., Gray, M., \& James, C. (2013). Factors That Influence the Professional Resilience of Occupational Therapists in Mental Health Practice. Australian Occupational Therapy Journal, 60, 110-119. https://doi.org/10.1111/1440-1630.12012

Boles, J. S., Dean, D. H., Ricks, J. M., Short, J. C., \& Wang, G. (2000). The Dimensionality of the Maslach Burnout Inventory across Small Business Owners and Educators. Journal of Vocational Behavior, 56, 12-34. https://doi.org/10.1006/jvbe.1999.1689

Bollen, K. A., \& Pearl, J. (2013). Eight Myths about Causality and Structural Equation Models. In S. L. Morgan (Ed.), Handbook of Causal Analysis for Social Research (pp. 301-328). New York: Springer. https://doi.org/10.1007/978-94-007-6094-3 15

Brown, T. A. (2015). Confirmatory Factor Analysis for Applied Research (2nd ed.). New York: Guilford Publications.

Byrne, B. M. (2012). Structural Equation Modeling with Mplus: Basic Concepts, Applications, and Programming. London: Routledge. https://doi.org/10.4324/9780203807644

Campbell-Sills, L., \& Stein, M. B. (2007). Psychometric Analysis and Refinement of the Connor-Davidson Resilience Scale (CD-RISC): Validation of a 10-Item Measure of Resilience. Journal of Traumatic Stress, 20, 1019-1028. https://doi.org/10.1002/jts.20271

Connor, K. M., \& Davidson, J. R. T. (2003). Development of a New Resilience Scale: The Connor-Davidson Resilience Scale (CD-RISC). Depression and Anxiety, 18, 71-82. https://doi.org/10.1002/da.10113

de Witt, P. A., Monareng, L., Abraham, A. A. H., Koor, S., \& Saber, R. (2019). Resilience in Occupational Therapy Students. South African Journal of Occupational Therapy, 49, 33-41. https://doi.org/10.17159/23103833/2019/vol49n2a6

Demerouti, E., Mostert, K., \& Bakker, A. B. (2010). Burnout and Work Engagement: A Thorough Investigation of the Independency of Both Constructs. Journal of Occupational Health Psychology, 15, 209-222. https://doi.org/10.1037/a0019408

Derakhshanrad, S. A., Piven, E., \& Ghoochani, B. Z. (2019). The Relationships between Problem-Solving, Creativity, and Job Burnout in Iranian Occupational Therapists. Occupational Therapy in Health Care, 33, 365-380. https://doi.org/10.1080/07380577.2019.1639098

Devery, H., Scanlan, J. N., \& Ross, J. (2018). Factors Associated with Professional Identity, Job Satisfaction and Burnout for Occupational Therapists Working in Eating Disorders: A Mixed Methods Study. Australian Occupational Therapy Journal, 65, 523-532. https://doi.org/10.1111/1440-1630.12503

Epskamp, S. (2019). semPlot: Path Diagrams and Visual Analysis of Various SEM Packages' Output. R Package Version 1.1.2. https://CRAN.R-project.org/package=semPlot

Feldt, L. S., Woodru, D. J., \& Salih, F. A. (1987). Statistical Inference for Coefficient Alpha. Applied Psychological Measurement, 11, 93-103. https://doi.org/10.1177/014662168701100107

Galanakis, M., Moraitou, M., Garivaldis, F. J., \& Stalikas, A. (2009). Factorial Structure and Psychometric Properties of the Maslach Burnout Inventory-Health Services Survey (MBI) in Greek Midwives. Europe's Journal of Psychology, 5, 52-70. https://doi.org/10.5964/ejop.v5i4.240

Giotsa, A., Kyriazos, T. A., \& Mitrogiorgou, E. (2018). Parental Acceptance-Rejection and Interpersonal Anxiety in Young Adults. Hellenic Journal of Psychology, 15, 138-150.

Glasberg, A. L., Eriksson, S., \& Norberg, A. (2007). Burnout and "Stress of Conscience" among Healthcare Personnel. Journal of Advanced Nursing, 57, 392-403.

https://doi.org/10.1111/j.1365-2648.2007.04111.x 
Gupta, S., Paterson, M. L., Lysaght, R. M., \& von Zweck, C. M. (2012). Experiences of Burnout and Coping Strategies Utilized by Occupational Therapists. Canadian Journal of Occupational Therapy, 79, 86-95. https://doi.org/10.2182/cjot.2012.79.2.4

Hendrickson, B. (1979). Teacher Burnout: How to Recognize It; What to Do about It. Learning, 7, 37-39.

Hu, L. T., \& Bentler, P. M. (1999). Cutoff Criteria for Fit Indexes in Covariance Structure Analysis: Conventional Criteria versus New Alternatives. Structural Equation Modeling, 6, 1-55. https://doi.org/10.1080/10705519909540118

Katsiana, A., Galanakis, M., Saprikis, V., Tsiamitros, D., \& Stalikas, A. (2021). Psychological Resilience and Burnout Levels in Occupational Therapists in Greece. An Epidemiological Nationwide Research. Psychology, 12, 84-106.

https://doi.org/10.4236/psych.2021.121006

Kline, R. B. (2016). Principles and Practice of Structural Equation Modeling (4th ed.). New York: The Guilford Press.

Kline, R. B. (2020). Becoming a Behavioral Science Researcher: A Guide to Producing Research That Matters. New York: The Guilford Press.

Kokkinos, C. M. (2006). Factor Structure and Psychometric Properties of the Maslach Burnout Inventory-Educators Survey among Elementary and Secondary School Teachers in Cyprus. Stress and Health, 22, 25-33. https://doi.org/10.1002/smi.1079

Kyriazos, T. (2017a). Reliability of Psychometric Instruments. In M. Galanakis, C. Pezirkianidis, \& A. Stalikas (Eds.), Basic Aspects of Psychometrics (pp. 85-126). Athens: Topos.

Kyriazos, T. (2017b). Validity of Psychometric Instruments. In M. Galanakis, C. Pezirkianidis, \& A. Stalikas (Eds.), Basic Aspects of Psychometrics (pp. 127-184). Athens: Topos.

Kyriazos, T. A. (2018). Applied Psychometrics: Writing-Up a Factor Analysis Construct Validation Study with Examples. Psychology, 9, 2503-2530.

https://doi.org/10.4236/psych.2018.911144

Kyriazos, T. A., \& Giotsa, A. (2019). Interpersonal Rejection Anxiety Questionnaire (IRAQ): Psychometric Properties of the Greek Version. Psychology, 10, 1542-1563. https://doi.org/10.4236/psych.2019.1011101

Kyriazos, T. A., \& Stalikas, A. (2018). Positive Parenting or Positive Psychology Parenting? Towards a Conceptual Framework of Positive Psychology Parenting. Psychology, 9, 1761-1788. https://doi.org/10.4236/psych.2018.97104

Kyriazos, T. A., \& Stalikas, A. (2019a). Alabama Parenting Questionnaire-Short Form (APQ-9): Evidencing Construct Validity with Factor Analysis, CFA MTMM and Measurement Invariance in a Greek Sample. Psychology, 10, 1790-1817.

https://doi.org/10.4236/psych.2019.1012117

Kyriazos, T. A., \& Stalikas, A. (2019b). Nicomachus-Positive Parenting (NPP): Development and Initial Validation of a Parenting Questionnaire within the Positive Psychology Framework. Psychology, 10, 2115-2165.

https://doi.org/10.4236/psych.2019.1015136

Kyriazos, T. A., Stalikas, A., Prassa, K., Galanakis, M., Flora, K., \& Chatzilia, V. (2018). The Flow Short Scale (FSS) Dimensionality and What MIMIC Shows on Heterogeneity and Invariance. Psychology, 9, 1357-1382. https://doi.org/10.4236/psych.2018.96083

Kyriazos, T. A., Stalikas, A., Prassa, K., Galanakis, M., Yotsidi, V., \& Lakioti, A. (2018). Psychometric Evidence of the Brief Resilience Scale (BRS) and Modeling Distinctiveness of Resilience from Depression and Stress. Psychology, 9, 1828-1857.

https://doi.org/10.4236/psych.2018.97107

Kyriazos, T. A., Stalikas, A., Prassa, K., Yotsidi, V., Galanakis, M., \& Pezirkianidis, C. 
(2018). Validation of the Flourishing Scale (FS), Greek Version and Evaluation of Two Well-Being Models. Psychology, 9, 1789-1813.

https://doi.org/10.4236/psych.2018.97105

Lasalvia, A., Bonetto, C., Bertani, M., Bissoll, S., Cristofalo, D., Marrella, G., Ruggeri, M. et al. (2009). Influence of Perceived Organizational Factors on Job Burnout: Survey of Community Mental Health Staff. The British Journal of Psychiatry, 195, 537-544. https://doi.org/10.1192/bjp.bp.108.060871

Lloyd, C., \& King, R. (2001). Work-Related Stress and Occupational Therapy. Occupational Therapy International, 8, 227-243. https://doi.org/10.1002/oti.148

Lloyd, C., \& King, R. (2004). A Survey of Burnout among Australian Mental Health Occupational Therapists and Social Workers. Social Psychiatry and Psychiatric Epidemiology, 39, 752-757. https://doi.org/10.1007/s00127-004-0808-7

MacCallum, R. C., Browne, M. W., \& Sugawara, H. M. (1996). Power Analysis and Determination of Sample Size for Covariance Structure Modeling. Psychological Methods, 1, 130. https://doi.org/10.1037/1082-989X.1.2.130

Maslach, C. (1976). Burned-Out. Human Behaviour, September, 16-22.

Maslach, C. (1978). Job Burnout-How People Cope. Public Welfare, Spring, 56-58.

Maslach, C. (1993) Burnout: A Multidimensional Perspective. In W. B. Schaufeli, C. Maslach, \& T. Marek (Eds.), Professional Burnout (pp. 19-32). Washington DC: Taylor and Francis. https://doi.org/10.4324/9781315227979-3

Maslach, C., Jackson, S., \& Leiter, M. (1996). Maslach Burnout Inventory Manual (3rd ed.). Palo Alto, CA: Consulting Psychological Press.

Masyn, K. E. (2013). Latent Class Analysis and Finite Mixture Modeling. In T. D. Little (Ed.), The Oxford Handbook of Quantitative Methods (pp. 551-611). New York: Oxford University Press. https://doi.org/10.1093/oxfordhb/9780199934898.013.0025

McAllister, M., \& McKinnon, J. (2009). The Importance of Teaching and Learning Resilience in the Health Disciplines: A Critical Review of the Literature. Nurse Education Today, 29, 371-379. https://doi.org/10.1016/j.nedt.2008.10.011

McDonald, R. P. (1999). Test Theory: A Unified Treatment. Mahwah, NJ: Erlbaum.

Notario-Pacheco, B., Solera-Martínez, M., Serrano-Parra, M. D., Bartolomé-Gutiérrez, R., García-Campayo, J., \& Martínez-Vizcaíno, V. (2011). Reliability and Validity of the Spanish Version of the 10-Item Connor-Davidson Resilience Scale (10-Item CD-RISC) in Young Adults. Health and Quality of Life Outcomes, 9, 63-68. https://doi.org/10.1186/1477-7525-9-63

Nulty, D. D. (2008). The Adequacy of Response Rates to Online and Paper Surveys: What Can Be Done? Assessment \& Evaluation in Higher Education, 33, 301-314. https://doi.org/10.1080/02602930701293231

Pines, A., \& Maslach, C. (1978). Characteristics of Staff Burnout on Mental Health Setting. Hospital and Community Psychiatry, 29, 233-237. https://doi.org/10.1176/ps.29.4.233

Poulsen, A. A., Meredith, P., Khan, A., Henderson, J., Castrisos, V., \& Khan, S. R. (2014). Burnout and Work Engagement in Occupational Therapists. British Journal of Occupational Therapy, 77, 156-164. https://doi.org/10.4276/030802214X13941036266621

R Development Core Team (2020). R: A Language and Environment for Statistical Computing. Vienna: R Foundation for Statistical Computing.

Ramaswamy, V., DeSarbo, W. S., Reibstein, D. J., \& Robinson, W. T. (1993). An Empirical Pooling Approach for Estimating Marketing Mix Elasticities with PIMS Data. Mar- 
keting Science, 12, 103-124. https://doi.org/10.1287/mksc.12.1.103

Reis, H., Vale, C., Camacho, C., Estrela, C., \& Anjos, M. (2018). Burnout among Occupational Therapists in Portugal: A Study of Specific Factors. Occupational Therapy in Health Care, 32, 1-15.

Rivard, A., \& Brown, C. A. (2019). Moral Distress and Resilience in the Occupational Therapy Workplace. Safety, 5, 10. https://doi.org/10.3390/safety5010010

Rosenberg, J. M., Beymer, P. N., Anderson, D. J., Van Lissa, C. J., \& Schmidt, J. A. (2018). tidyLPA: An R Package to Easily Carry Out Latent Profile Analysis (LPA) Using Open-Source or Commercial Software. Journal of Open Source Software, 3, 978. https://doi.org/10.21105/joss.00978

Rosseel, Y. (2012). lavaan: An R Package for Structural Equation Modeling. Journal of Statistical Software, 48, 1-36. https://www.jstatsoft.org/article/view/v048i02 https://doi.org/10.18637/jss.v048.i02

Saaty, T. L. (1990). An Exposition of the AHP in Reply to the Paper "Remarks on the Analytic Hierarchy Process". Management Science, 36, 259-268.

https://doi.org/10.1287/mnsc.36.3.259

Scanlan, J. N., \& Hazelton, T. (2019). Relationships between Job Satisfaction, Burnout, Professional Identity and Meaningfulness of Work Activities for Occupational Therapists Working in Mental Health. Australian Occupational Therapy Journal, 66, 581-590. https://doi.org/10.1111/1440-1630.12596

Scanlan, J. N., \& Still, M. (2013). Job Satisfaction, Burnout, and Turnover Intention in Occupational Therapists Working in Mental Health. Australian Occupational Therapy Journal, 60, 310-318. https://doi.org/10.1111/1440-1630.12067

Schlenz, K., Guthrie, M., \& Dudgeon, B. (1995). Burnout in Occupational and Physical Therapists Working in Head Injury Rehabilitation. American Journal of Occupational Therapy, 49, 986-993. https://doi.org/10.5014/ajot.49.10.986

Schmitt, A., Zacher, H., \& Frese, M. (2012). The Buffering Effect of Selection, Optimization, and Compensation Strategy Use on the Relationship between Problem Solving Demands and Occupational Well-Being: A Daily Diary Study. Journal of Occupational Health Psychology, 17, 139-149. https://doi.org/10.1037/a0027054

Schumacker, R. E., \& Lomax, R. G. (2015). A Beginner's Guide to Structural Equation Modeling (4th ed.). New York: Routledge. https://doi.org/10.4324/9781315749105

Smith, B. W., Tooley, E. M., Christopher, P. J., \& Kay, V. S. (2010). Resilience as the Ability to Bounce Back from Stress: A Neglected Personal Resource? The Journal of Positive Psychology, 5, 166-176. https://doi.org/10.1080/17439760.2010.482186

Stalikas, A., \& Kyriazos, T. (2019). Research Methods and Statistics Using R. Athens, GR: Topos.

Stalikas, A., Kyriazos, T. A., Yotsidi, V., \& Prassa, K. (2018). Using Bifactor EFA, Bifactor CFA and Exploratory Structural Equation Modeling to Validate Factor Structure of the Meaning in Life Questionnaire, Greek Version. Psychology, 9, 348-371. https://doi.org/10.4236/psych.2018.93022

Sturgess, J., \& Poulsen, A. (1983). The Prevalence of Burnout in Occupational Therapists. Occupational Therapy in Mental Health, 3, 47-60. https://doi.org/10.1300/J004v03n04 05

Sweeney, G., Nichols, K., \& Cormack, M. (1993). Job Stress in Occupational Therapy: Coping Strategies, Stress Management Techniques and Recommendations for Change. British Journal of Occupational Therapy, 56, 140-145. https://doi.org/10.1177/030802269305600409 
Tugade, M. M., \& Fredrickson, B. L. (2007). Regulation of Positive Emotions: Emotion Regulation Strategies that Promote Resilience. Journal of Happiness Studies, 8, 311-333. https://doi.org/10.1007/s10902-006-9015-4

Wang, J., \& Wang, X. (2020). Structural Equation Modeling (2nd ed.). Hoboken, NJ: Wiley, Higher Education Press.

Yotsidi, V., Pagoulatou, A., Kyriazos, T., \& Stalikas, A. (2018). The Role of Hope in Academic and Work Environments: An Integrative Literature Review. Psychology, 9, 385-402. https://doi.org/10.4236/psych.2018.93024

\section{Appendix}

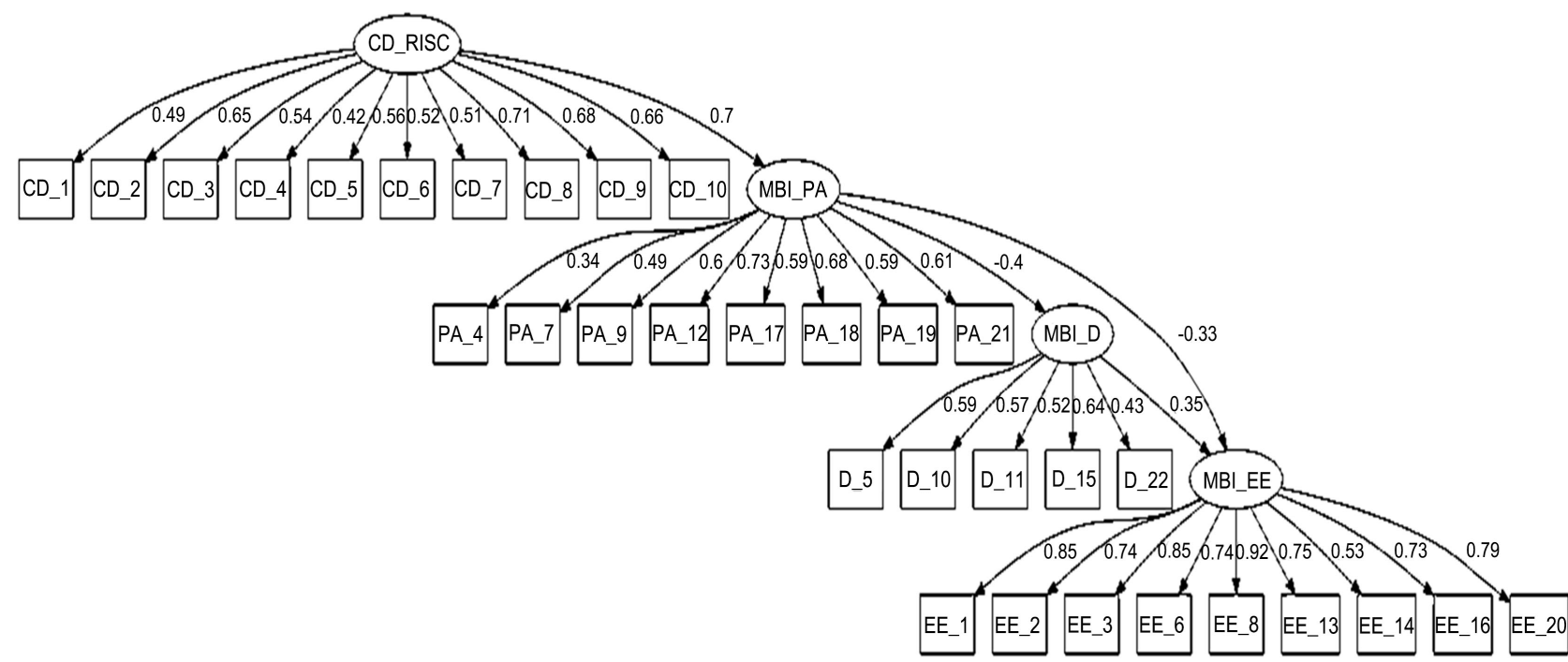

Figure A1. The path diagram of the proposed full SEM model (standardized coefficients, all $p s<0.001$ ). 